\title{
Comparison of the Static and Dynamic Balance Between Normal-Hearing and Hearing- Impaired Wrestlers
}

\author{
Betul Coskun ${ }^{1}$, Gurcan Unlu ${ }^{1}$, Bahman Golshaei ${ }^{1}$, Settar Kocak ${ }^{1}$, Sadettin Kirazci ${ }^{1}$
}

\begin{abstract}
Affiliations: 'Middle East Technical University, Faculty of Education, Department of Physical Education and Sports, Ankara, Turkey

Correspondence: B. Coskun, Middle East Technical University, Department of Physical Education and Sports, 06800 Cankaya/Ankara, Turkey. E-mail: bcoskun@metu.edu.tr
\end{abstract}

ABSTRACT Balance is fundamental in sport, especially when there is an opponent. Although balance can be improved with practice, it is highly affected by nervous system disorders, particularly by vestibular disorders and visual impairment. The purpose of this study was to compare static and dynamic balance between nor$\mathrm{mal}$ and hearing-impaired wrestlers. The participants were 52 young male hearing-impaired wrestlers $(\mathrm{n}=29$, age $=18.76 \pm 3.54)$ and normal-hearing athletes $(n=23$, age $=19.09 \pm 2.76)$ competing at the national level. The static and dynamic balance were measured using the stork test on one foot and the Y-balance test (in anterior, posteromedial \& posterolateral directions). MANOVA indicated significant differences between groups (Wilks' $\mathrm{L}=.284$, $\left.\mathrm{F}_{12.39}=8.21, \mathrm{p}<.05, \eta^{2}=.72\right)$. Differences were detected in how long the participant had been active in the sport $\mathrm{F}$ (year) $\left(\mathrm{F}_{1,50}=145.95, \mathrm{p}<.025, \eta^{2}=.75\right)$ and right leg static balance $\left(\mathrm{F}_{1,50}=73.63, \mathrm{p}<.025, \eta^{2}=.60\right)$. As for the $\mathrm{Y}$ balance test, there was also a significant difference in the anterior direction for the right leg $\left(\mathrm{F}_{1,50}=4880.66, \mathrm{p}<.025\right.$, $\left.\eta^{2}=.99\right)$ and left leg $\left(\mathrm{F}_{1,50}=3563.87, \mathrm{p}<.025, \eta^{2}=.99\right)$. Hearing-impaired wrestlers performed better balance abilities in the dynamic balance test of right and left legs in the anterior direction. In contrast, the amount of time active in the sport and the static balance of the right leg were found better in normal-hearing wrestlers. Being better than normal wrestlers only in the anterior direction of the dynamic balance might be due to the differences related to the directions of the test. Future studies are recommended for investigating the reasons for this difference.

KEY WORDS balance, hearing-impaired, wrestlers

O

@MJSSMontenegro

THE STATIC AND DYNAMIC BALANCE BETWEEN WRESTLERS

http://mjssm.me/?sekcija=article\&artid=167

Introduction

Balance is the task of keeping the position of the centre of gravity of the body vertical, and then performing coordinated and precise neuromuscular activities based on the fast and sustained feedback from visual, vestibular, and somatosensory constructions (Hrysomallis, 2011). Static balance is the skill of sustaining a base of support with minimum movement. Dynamic balance is the skill of executing an action while maintaining a stable position or the skill of sustaining one's balance on an unstable surface (Bressel, Yonker, Kras, \& Heath, 2007; Hrysomallis, 2011).

Balance, the precursor of voluntary motor activity, requires the efficient operation and interaction of vestibular, proprioceptive, motor and visual neurophysiological mechanisms (McLeod \& Hansen, 1989), in that it is an act of integrating sensory input from various sources to provide static and dynamic postures (Fotiadou et al., 2002). For the completion of balance, a combination of sensory, vestibular, visual, proprioceptive systems, the central nervous system, and the musculoskeletal system is needed (Winter, Patla, \& Frank, 1990). The proprioceptive system is composed of muscles, joints and cutaneous receptors. It gives information about the effector system from muscles and other body parts, and also about the environment (Winter et al., 1990). Input from the eyes provides information about how the individual is positioned in respect to the surrounding objects and about the position and movement of the head (Hosseinimehr, Norasteh, Abbasi, Tazji, \& Hosseinimehr, 2009;

Received: March 032018 | Accepted after revision: April 052018 | First published online: March 012019

(C) 2018 by the author(s). License MSA, Podgorica, Montenegro. This article is an open access article distributed under the terms and conditions of the Creative Commons Attribution (CC BY).

Conflict of interest: None declared. 
Vestibular Disorder Association (VEDA), 2008). As for the sensory information related to movement, balance, and spatial orientation, it is provided by vestibular organs: the saccule, the utricle, and three semi-circular canals in the ear. While the saccule and utricle perceive the gravity and linear motion, the semi-circular canals specify the rotational movements. The balance information acquired from these peripheral sensory organs is transmitted to the brain stem. Then, it is analysed and integrated with learned information with the contributions of the cerebellum and the cerebral cortex (VEDA, 2008), and the proper movement plan is performed by the musculoskeletal system to organize the action and body posture (Winter et al., 1990).

This complexity of the balance system promotes the detection and treatment of the underlying reasons of balance disorders, and vestibular disorders are in the lead as a reason (VEDA, 2008). Therefore, studies with hearing impairments have gained importance. Hearing-impaired individuals, in comparison to normal-hearing ones, are more vulnerable with regards to static balance, dynamic coordination of the body, simultaneous movements of limbs and movement speed (Effgen, 1981; Fotiadou et al., 2002; Kitiş, Büker, Eren, \& Aydın, 2015; Wiegersma \& Velde, 1983; Yağc1, Cavlak, \& Şahin, 2004). This impaired balance may affect the acquisition of other motor skills and may hinder visual-perceptual motor development and sensory integration (Effgen, 1981). However, sport is a recommended method for reducing these negative effects, facilitating daily life activities and the rehabilitation of hearing-impaired individuals (Yağc1 et al., 2004). Balance is fundamental, especially in combat sports, in which the balance is kept against the opponent (El Rendimiento, 2015; Leong, Fu, Ng, \& Tsang, 2011; Perrin, Deviterne, Hugel, \& Perrot, 2002; Perrot, Mur, Mainard, Barrault, \& Perrin, 2000). In Olympic wrestling, athletes must effectively maintain their static and dynamic balance due to the techniques of this sport which are based on changing of location, pushing and pulling in order to disturb the opponent's balance (El Rendimiento, 2015). Therefore, the balance of athletes is better than sedentary individuals especially in combat sports (Bieć \& Kuczyński, 2010; Filingeri, Bianco, Zangla, Paoli, \& Palma, 2012; Leong et al., 2011; Perrin et al., 2002; Perrot, Moes, Deviterne, \& Perrin, 1998). However, although the balance can be improved by sports, it is highly affected by nervous system disorders, visual impairment, fatigue and mental conditions and, as stated previously, particularly by vestibular disorders (Fotiadou et al., 2002; Yağc1 et al., 2004). Therefore, the purpose of this study is to compare static and dynamic balance between normal and hearing-impaired wrestlers.

\section{Methods}

\section{Participants}

Fifty-two young male wrestlers, including hearing-impaired ( $\mathrm{n}=29$, age $=18.76 \pm 3.54$ years) and normal-hearing athletes $(n=23$, age $=19.09 \pm 2.76$ years), who are athletes on the Turkish National Team voluntarily participated in the study. Thus, a purposive sampling method was used. All participants completed informed consent forms. The human research ethics committee at the Middle East Technical University approved the study. Both groups consisted of freestyle and Greco-Roman wrestlers in junior and senior categories. Information about their age, height, weight, the amount of time active in the sport and previous injuries was obtained from participants and reviewed. Those who had been injured in the previous three months were excluded from the study.

\section{Procedures}

The measurements of both groups were taken at the same time of day and on days when there was no wrestling training. Short warm-up times were given to the participants before starting to test. Then static balance was measured by using the stork test on one foot. The participant removed his shoes, placed his hands on his waist, and placed the unsupported leg towards the interior of the knee of the support leg. He was asked to lift his heel from the floor and try to balance on tiptoe. The stopwatch was started when the heel was removed from the floor. The researcher stood behind the participant due to the possibility of the latter's losing his balance and falling. Participants were warned not to lower their hands and not to turn their support leg in any direction or to bounce. Furthermore, it was said that the test would be stopped when there was a disconnection between the unsupported leg and knee, and when the heel of the support leg touched the ground. To make a comparison, both sides, right and left, were evaluated. It was tested two times for both feet, and the best value was recorded in seconds (Reiman \& Manske, 2009).

As for the dynamic balance, the Y-Balance Test (YBT) was used. It is a test to measure the dynamic balance in unilateral standing and a variation of the Star Excursion Balance Test. The participant tried to reach in the anterior, posteromedial, and posterolateral directions while standing on one foot at the exact centre of the test platform. Both left and right legs were tested when barefoot. Participants were allowed four trials, then measurements were performed three times in all directions. The participants were asked to try to reach as far as possible with one foot while standing on the other foot just behind the start line. To accomplish the measurement, participants were warned not to lower their test-foot before returning to the stance-position and not to try to speed up to reach further. Furthermore, they were instructed that the trial would be regarded as invalid if they stepped on the reach point to get support or if they lost their balance before returning to the starting position. The average of the three trials was normalized to leg length. Also, the reach distances in three directions were summed to determine the total performance of both feet. The rest interval time between trials was sufficient for the reach distance to be recorded and for starting once again (Butler, Southers, Gorman, Kiesel, \& Plisky, 2012). 
Statistical analysis

The statistics of variables were reported by using mean and standard deviation. The normality of distribution was tested with a Shapiro-Wilk test. To compare the differences in balance parameters between the normal-hearing and hearing-impaired groups, One-way Multivariate Analysis of Variance (One-way MANOVA) was used. IBM SPSS Statistics v22.0 was used for statistical data analyses. Alpha value was accepted as 0.05.

Results

There are significant differences between the groups (Wilks' $\mathrm{L}=.284, \mathrm{~F}_{12,39}=8.21, \mathrm{p}<.05, \eta^{2}=.72$ ) (Table 2). One of these differences was detected in the amount of time active in the sport (year) $\left(\mathrm{F}_{1,50}=145.95, \mathrm{p}<.025, \eta^{2}=.75\right.$ ) (Table 1).

\begin{tabular}{|c|c|c|c|c|c|c|}
\hline Variable & Group & $\mathbf{n}$ & $\mathrm{X} \pm \mathrm{SS}$ & $\mathbf{F}$ & $\mathbf{p}$ & $\eta 2$ \\
\hline \multirow{2}{*}{ Age (year) } & Hearing-impaired & 29 & $18,76 \pm 3,54$ & \multirow{2}{*}{13} & \multirow{2}{*}{,717 } & \multirow{2}{*}{,003 } \\
\hline & Normal-hearing & 23 & $19,09 \pm 2,76$ & & & \\
\hline \multirow{2}{*}{ Height (cm) } & Hearing-impaired & 29 & $171,41 \pm 8,79$ & \multirow{2}{*}{4,51} & \multirow{2}{*}{,039 } & \multirow{2}{*}{08} \\
\hline & Normal-hearing & 23 & $176,22 \pm 7,14$ & & & \\
\hline \multirow{2}{*}{ Weight (kg) } & Hearing-impaired & 29 & $70,72 \pm 17,75$ & \multirow{2}{*}{5,03} & \multirow{2}{*}{,029 } & \multirow{2}{*}{,09 } \\
\hline & Normal-hearing & 23 & $82,52 \pm 20,13$ & & & \\
\hline \multirow{2}{*}{$\begin{array}{l}\text { Time active } \\
\text { in the sport (year) }\end{array}$} & Hearing-impaired & 29 & $4,43 \pm 4,02$ & \multirow{2}{*}{11,82} & \multirow{2}{*}{, $001^{* *}$} & \multirow{2}{*}{19} \\
\hline & Normal-hearing & 23 & $7,96 \pm 3,18$ & & & \\
\hline
\end{tabular}

Note. ${ }^{* *} \mathrm{p}<0.025$

TABLE 2 One-Way MANOVA Test Results

\begin{tabular}{lcccccc} 
Variable & $\boldsymbol{\lambda}$ & $\mathbf{F}$ & df & Error df & $\mathbf{p}$ & $\mathbf{\eta 2}$ \\
\hline Hearing impairment &, 284 & 8,21 & 12 & 39 &, $001^{*}$ &, 72 \\
\hline
\end{tabular}

Note. $\lambda$ :Wilks' Lambda, ${ }^{*} \mathrm{p}<0.05$

Furthermore, a significant difference was found in the static balance of the right leg $\left(\mathrm{F}_{1,50}=73.63, \mathrm{p}<.025\right.$, $\eta^{2}=.60$ ) (Table 3). As for the Y-balance test, there was also a significant difference in the anterior direction for the right leg $\left(\mathrm{F}_{1,50}=4880.66, \mathrm{p}<.025, \eta^{2}=.99\right)$ and the left leg $\left(\mathrm{F}_{1,50}=3563.87, \mathrm{p}<.025, \eta^{2}=.99\right)$ (Table 3$)$.

\begin{tabular}{|c|c|c|c|c|c|c|}
\hline Variable & Group & $\mathbf{n}$ & $\mathrm{X} \pm \mathrm{SS}$ & $\mathbf{F}$ & $\mathbf{p}$ & $\eta 2$ \\
\hline \multirow{2}{*}{ Static right } & Hearing-impaired & 29 & $4,59 \pm 3,31$ & \multirow{2}{*}{12,62} & \multirow{2}{*}{, $001^{* *}$} & \multirow{2}{*}{20} \\
\hline & Normal-hearing & 23 & $11,08 \pm 9,13$ & & & \\
\hline \multirow{2}{*}{ Static left } & Hearing-impaired & 29 & $6,30 \pm 6,81$ & \multirow{2}{*}{3,50} & \multirow{2}{*}{, 067} & \multirow{2}{*}{07} \\
\hline & Normal-hearing & 23 & $10,06 \pm 7,67$ & & & \\
\hline \multirow{2}{*}{ Right anterior } & Hearing-impaired & 29 & $91,39 \pm 8,91$ & \multirow{2}{*}{19,30} & \multirow{2}{*}{, $001^{* *}$} & \multirow{2}{*}{, 28} \\
\hline & Normal-hearing & 23 & $80,57 \pm 8,70$ & & & \\
\hline \multirow{2}{*}{ Left anterior } & Hearing-impaired & 29 & $94,33 \pm 9,03$ & \multirow{2}{*}{31,59} & \multirow{2}{*}{, $001^{* *}$} & \multirow{2}{*}{39} \\
\hline & Normal-hearing & 23 & $78,10 \pm 11,81$ & & & \\
\hline \multirow{2}{*}{ Right posteromedial } & Hearing-impaired & 29 & $135,39 \pm 18,94$ & \multirow{2}{*}{, 16 } & \multirow{2}{*}{ 692 } & \multirow{2}{*}{, 00 } \\
\hline & Normal-hearing & 23 & $133,65 \pm 10,12$ & & & \\
\hline \multirow{2}{*}{ Left posteromedial } & Hearing-impaired & 29 & $139,80 \pm 19,47$ & \multirow{2}{*}{1,04} & \multirow{2}{*}{,314 } & \multirow{2}{*}{,02 } \\
\hline & Normal-hearing & 23 & $135,15 \pm 11,31$ & & & \\
\hline \multirow{2}{*}{ Right posterolateral } & Hearing-impaired & 29 & $126,77 \pm 21,10$ & \multirow{2}{*}{23} & \multirow{2}{*}{,633 } & \multirow{2}{*}{01} \\
\hline & Normal-hearing & 23 & $129,04 \pm 9,27$ & & & \\
\hline \multirow{2}{*}{ Left posterolateral } & Hearing-impaired & 29 & $129,94 \pm 19,23$ & \multirow{2}{*}{,71 } & \multirow{2}{*}{,403 } & \multirow{2}{*}{01} \\
\hline & Normal-hearing & 23 & $133,67 \pm 9,94$ & & & \\
\hline \multirow{2}{*}{$\begin{array}{l}\text { Right total } \\
\text { performance }\end{array}$} & Hearing-impaired & 29 & $353,55 \pm 43,01$ & \multirow{2}{*}{1,05} & \multirow{2}{*}{,310 } & רח \\
\hline & Normal-hearing & 23 & $343,27 \pm 24,09$ & & & , 02 \\
\hline Left total & Hearing-impaired & 29 & $364,08 \pm 41,11$ & 296 & 091 & 06 \\
\hline performance & Normal-hearing & 23 & $346,91 \pm 27,36$ & 2,0 & & \\
\hline
\end{tabular}

Note. ${ }^{* *} \mathrm{p}<0.025$ 


\section{Discussion}

The study aimed to determine whether the hearing impairment makes a difference in the static and dynamic balance of elite wrestlers. Significant differences were found between the groups of wrestlers with and without hearing impairment. Normal-hearing athletes were found to be better in terms of the amount of time they had been active in the sport and static balance measured with the right foot. In a study conducted on hearing-impaired male volleyball and handball players, a significant difference was found in the balance scores of the groups in favour of the volleyball players, and this difference was thought to be due to the structure of volleyball and the greater amount of time they had been active in the sport, which is similar in the present study (Taşkın, Karakoç, \& Yüksek, 2015). In another study made on hearing-impaired and normal-hearing children, the hearing-impaired ones were found to be significantly weaker than normal-hearing ones in static balance (Shaikh \& Sadhale, 2013). A different study was conducted on three different groups as hearing-impaired sedentary and football players and normal-hearing football players. It was found that normal-hearing football players were better in static balance performance than hearing-impaired football players were (Eliöz, Sitti, Koç, Murt, \& Koç, 2013). Yağc1 et al. (2004) carried out a study on children with and without hearing impairment and evaluated the balance scores by use of dynamic and static balance tests on stable and unstable surfaces. They concluded that normal-hearing group had the best scores while the group with congenital hearing impairment had the lowest scores. Studies indicate that hearing-impaired individuals have the weaker balance ability than normal-hearing ones, especially in static balance (Tan, Nonis, \& Chow, 2011) and the present study findings, are consistent with the literature in this respect. Because deafness can affect the psychomotor integration of the central nervous system and impair motor skills like balance (Lindsey \& O'Neal, 1976), it was thought that the weaker static balance of the hearing-impaired group was due to their hearing impairment. Additionally, it might be influenced by the lower amount of time active in the sport and also the difference just in the right foot measurement may be related to the dominant side of the groups.

As for the dynamic balance, it was found that hearing-impaired wrestlers had better balance abilities just in the anterior direction in both right and left leg measurements. In the literature, while some studies show no significant differences between hearing-impaired and normal-hearing groups (Gayle \& Pohlman, 1990; Melo, Silva, Tassitano, Macky, \& Silva, 2012; Nakajima, Kaga, Takekoshi, \& Sakuraba, 2012), studies showing significant differences are also available (Gayle \& Pohlman, 1990; Kitiş et al., 2015; Tan et al., 2011; Yağc1 et al., 2004). However, these differences are generally in favour of the normal-hearing group. The present study differs from the literature in this respect. For instance, in a different study, there was a significant difference in favour of the normal-hearing group in the balance to the left and toward the front, and also in total balance, while there was no significant difference in the balance scores to the right and backwards. It was thought that the reason for this non-existence of difference to the right and backwards was due to the fact that $70 \%$ of the participants in the hearing-impaired group had regular exercise habits and only $24.1 \%$ of the participants in the normal-hearing group were regularly exercising (Kitiş et al., 2015). However, in the present study, both groups are athletes from the Turkish National Team, so the exercise factor is not considered to be a reason for this difference.

It is not correct to say that the loss of balance in hearing-impaired individuals is due solely to vestibular system impairment; other factors need to be considered (Wiegersma \& Velde, 1983; Yağc1 et al., 2004). For instance, in another study, there was no significant difference between the groups in the one-leg standing test with eyes open; however, when performing the same test with eyes closed, the duration of standing was markedly shorter in the hearing-impaired group (Nakajima et al., 2012). When hearing impairment occurs, other sensory perceptions work to recompense the deficit (Nakajima et al., 2012; Siegel, Marchetti, \& Tecklin, 1991). Likewise, in another study conducted by using the one-leg-standing test with eyes closed, hearing-impaired individuals were found to be particularly weaker in balance (Tan et al., 2011). The underlying reason was thought to be the visual system. To control and maintain the balance depend on the inputs from visual, vestibular and somatosensory systems, and the combination of these systems within the environment. Studies showed that removing the visual stimulus negatively affects the hearing-impaired individuals more as they attempt to control their balance (Tan et al., 2011). As for the present study, the existence of significant differences in dynamic balance in favour of the hearing-impaired group may be due to the fact that other sensory systems improved much better to compensate for this deficit, also caused by the differences of strength, flexibility, and the dominant side. Especially for the anterior direction, better performances of dynamic balance test (Star Excursion Balance Test) were found related to the greater hip flexor, extensor, and abductor strength (Ambegaonkar, Mettinger, Caswell, Burtt, \& Cortes, 2014). In other respects, the weaker static balance but better dynamic balance ability, which was performed by the hearing-impaired group, may be explained with the source of the hearing impairment, since the saccule and utricle perceive the gravity and linear motion, while the semi-circular canals specify the rotational movements (Vestibular Disorder Association (VEDA), 2008).

Consequently, for hearing-impaired wrestlers, being better than normal-hearing wrestlers in the only anterior direction of the dynamic balance might be due to the differences related to the directions of the test and the differences of strength. The reasons for this difference should be investigated in future studies. Therefore, future studies are advised to take extra measurements such as strength and flexibility with balance tests and to obtain information about the dominant side of the participants. 
Acknowledgements

The abstract of this study was presented as an oral presentation at the $14^{\text {th }}$ International Sports Sciences Congress in Turkey.

\section{REFERENCES}

Ambegaonkar, J. P., Mettinger, L. M., Caswell, S. V., Burtt, A., \& Cortes, N. (2014). Relationships between core endurance, hip strength, and balance in collegiate female athletes. International Journal of Sports Physical Therapy, 9(5), 604-616.

Bieć, E., \& Kuczyński, M. (2010). Postural control in 13-year-old soccer players. European Journal of Applied Physiology, 110(4), 703-708.

Bressel, E., Yonker, J. C., Kras, J., \& Heath, E. M. (2007). Comparison of static and dynamic balance in female collegiate soccer, basketball, and gymnastics athletes. Journal of Athletic Training, 42(1), 42.

Butler, R. J., Southers, C., Gorman, P. P., Kiesel, K. B., \& Plisky, P. J. (2012). Differences in soccer players' dynamic balance across levels of competition. Journal of Athletic Training, 47(6), 616-620.

Effgen, S. K. (1981). Effect of an exercise program on the static balance of deaf children. Physical Therapy, 61(6), 873-877.

El Rendimiento, E. L. O. (2015). Can balance skills predict Olympic wrestling performance?. Journal of Sport and Health Research, 7(1), 19-30.

Eliöz, M., Sitti, S., Koç, M. C., Murt, Z., \& Koç, H. (2013). A Study on Static Balance Performance of Healthy and Hearing-Impaired Football Players. European Journal of Applied Sciences, 5(1), 25-28.

Filingeri, D., Bianco, A., Zangla, D., Paoli, A., \& Palma, A. (2012). Is karate effective in improving postural control?. Science of Martial Arts. 8(4), 191-4.

Fotiadou, E., Giagazoglou, P., Kokaridas, D., Angelopoulou, N., Tsimaras, V., \& Tsorbatzoudis, C. (2002). Effect of rhythmic gymnastics on the dynamic balance of children with deafness. European Journal of Special Needs Education, 17(3), 301-309.

Gayle, G. W., \& Pohlman, R. L. (1990). Comparative study of the dynamic, static, and rotary balance of deaf and hearing children. Perceptual and Motor Skills, 70(3), 883-888.

Hosseinimehr, S. H., Norasteh, A. A., Abbasi, A., Tazji, M. K., \& Hosseinimehr, S. H. (2009). The comparision of dependency on vision and proprioception in gymnastic, wrestling and soccer. Brazilian Journal of Biomotricity, 3(4), 332-338.

Hrysomallis, C. (2011). Balance ability and athletic performance. Sports Medicine, 41(3), 221-232.

Kitiş, A., Büker, N., Eren, K. E., \& Aydın, H. (2015). İşitme engelli kişilerde statik dengeyi etkileyen faktörlerin incelenmesi. Journal of Kartal Training \& Research Hospital, 26(1).

Leong, H. T., Fu, S. N., Ng, G. Y., \& Tsang, W. W. (2011). Low-level Taekwondo practitioners have better somatosensory organisation in standing balance than sedentary people. European Journal of Applied Physiology, 111(8), 1787-1793.

Lindsey, D., \& O’Neal, J. (1976). Static and dynamic balance skills of eight year old deaf and hearing children. American Annals of the Deaf, 49-55.

McLeod, B., \& Hansen, E. (1989). Effects of the eyerobics visual skills training program on static balance performance of male and female subjects. Perceptual and Motor Skills, 69(3 suppl), 1123-1126.

Melo, R. D. S., Silva, P. W. A. D., Tassitano, R. M., Macky, C. F. S., \& Silva, L. V. C. D. (2012). Balance and gait evaluation: comparative study between deaf and hearing students. Revista Paulista de Pediatria, 30(3), 385-391.

Nakajima, Y., Kaga, K., Takekoshi, H., \& Sakuraba, K. (2012). Evaluation of vestibular and dynamic visual acuity in adults with congenital deafness. Perceptual and Motor Skills, 115(2), 503-511.

Perrin, P., Deviterne, D., Hugel, F., \& Perrot, C. (2002). Judo, better than dance, develops sensorimotor adaptabilities involved in balance control. Gait and Posture, 15(2), 187-194.

Perrot, C., Moes, R., Deviterne, D., \& Perrin, P. (1998). Postural adaptations during specific combative sport movements. Science and Sports, 2(13), 64-74.

Perrot, C., Mur, J. M., Mainard, D., Barrault, D., \& Perrin, P. H. (2000). Influence of trauma induced by judo practice on postural control. Scandinavian Journal of Medicine and Science in Sports, 10(5), 292-297.

Reiman, M. P., \& Manske, R. C. (2009). Functional testing in human performance. Human Kinetics.

Shaikh, A. A., \& Sadhale, A. (2013). Motor proficiency in hearing impaired and healthy children: a comparison. International Journal of Current Research and Review, 5(11), 57.

Siegel, J. C., Marchetti, M., \& Tecklin, J. S. (1991). Age-related balance changes in hearing-impaired children. Physical Therapy, 71(3), 183-189.

Tan, J. S. Y., Nonis, K. P., \& Chow, J. Y. (2011). The balance control of children with and without hearing impairment in Singapore-A case study. International Journal of Special Education, 26(3).

Taşkın, C., Karakoç, Ö., \& Yüksek, S. (2015). İşitme engelli voleybol ve hentbol erkek sporcuların statik denge performans durumlarının incelenmesi. The Journal of Academic Social Science, 3(17), 248-255.

Vestibular Disorder Association. (2008). The human balance system: A complex coordination of central and peripheral systems. Retrieved from www.vestibular.org

Wiegersma, P. H., \& Velde, A. V. (1983). Motor development of deaf children. Journal of Child Psychology and Psychiatry, 24(1), 103-111. 
Winter, D. A., Patla, A. E., \& Frank, J. S. (1990). Assessment of balance control in humans. Medical Progress Through Technology, 16(1-2), 31-51.

Yağc1, N., Cavlak, U., \& Şahin, G. (2004). İşitme engellilerde denge yeteneğinin incelenmesi üzerine bir çalışma. Kulak, Burun, Boğaz ve Baş, Boyun Cerrahisi Dergisi, 3(2), 45-50. 